\title{
Scaling up the Ebola Response: What we Learned from AIDS Activism
}

\section{Chan J*}

Department of Educational Studies, Faculty of Education, University of British Columbia, Canada

*Corresponding author: Chan J, Department of Educational Studies, Faculty of Education, University of British Columbia, Canada, Fax: (604) 822-4244, Tel: (604) 731-8822, E-mail: Jennifer.chan@ubc.ca

Citation: Chan J (2015) Scaling up the Ebola Response: What we Learned from AIDS Activism. J Aids Hiv Infec 1(1): 104. doi: 10.15744/2454-499X.1.104

Received Date: February 20, 2015 Accepted Date: April 01, 2015 Published Date: April 08, 2015

\begin{abstract}
Thirty years of AIDS activism have taught us many invaluable lessons in responding to rapidly evolving global health epidemics. In this article, I apply five of them-innovative governance and financing; alternative incentives for biomedical research and development on neglected diseases; health systems strengthening; community and civil society engagement; and human rights protection-to the current Ebola epidemic. Despite very different contexts and demographics, there is a striking resemblance between the AIDS and Ebola epidemics in the major governance, funding, health systems, community mobilization, and human rights issues that impede an effective response to the current Ebola crisis.
\end{abstract}

Keywords: Ebola; AIDS; Activism

\section{Introduction}

\section{Learning from AIDS Activism in the Current Ebola Epidemic}

In the 30 years I've been working in public health, the only thing like this [Ebola] has been AIDS. We have to work now so this is not the world's next AIDS.

Dr. Tom Frieden, director of the U.S. Centers for Disease Control and Prevention [1].

By mid-March 2015, the current Ebola outbreak in Guinea, Liberia, and Sierra Leone has reported over 24,000 cases with close to 10,000 deaths including 491 health workers [2]. The highest number of cases is found in Sierra Leone where incidence has now stabilized, followed by Guinea and Liberia with a steep decline in confirmed cases. Six other countries (Mali, Nigeria, Senegal, Spain, the United Kingdom and the United States of America) have documented a case or cases imported from a country with high transmission. The current epidemic with the first case reported in March 2014 has now killed more than all other known Ebola outbreaks combined since the discovery of the virus in 1976. The human, economic, and social costs have been significant. Besides the high number of deaths, the health systems and resources in the three most affected countries have been stretched thin. The need for isolation for confirmed or suspected cases has greatly impacted regular commercial and agricultural activities. Foreign mining companies have withdrawn non-essential staff members, while several airlines have suspended flights to the affected areas.

There is widespread acknowledgement among governments and international agencies that the international response to the Ebola crisis has been slow, disorganised, and underfunded.

For many, the current failure is reminiscent of the AIDS struggle over 30 years ago. "HIV and Ebola are both viruses. Both emerged in Africa," explained Dr. Amesh Adalja, a representative of the Infectious Diseases Society of America. "Neither has a vaccine, and both are fatal if left untreated. Both are carried by host animals and then transmitted to humans, and both may have made that transition when hunters ate bush meat [1]". The two viruses are different in that HIV has a long latency period of up to ten years during which an infected person is able to transmit the disease, whereas Ebola has a much shorter latency period of around twenty-one days. But what has been so strikingly similar beyond the epidemiological properties of the two infectious viruses are the messy governance issues (decision-making concerning responsibility and funding) surrounding the current Ebola crisis, massive underfunding, the lack of industry interest in investing in vaccines or treatment for an "African" virus, fragile health systems, poor community engagement, and debilitating stigma and discrimination that kill as much as the virus itself. Below, I draw upon my study of 30 years of AIDS activism [3] to look at lessons learned for the current Ebola epidemic in governance, biomedical research, health systems, community engagement, and human rights protection.

\section{Innovative Governance and Financing}

The world is "dangerously unprepared" for future deadly pandemics like the Ebola outbreak in West Africa. Dr. Jim Yong Kim, president of the World Bank at the 2015 World Economic Forum [4]. 
Researchers have traced the current Ebola outbreak to a two-year-old toddler who died in December 2013 in Meliandou in southeastern Guinea [5]. The initial emergency response on the ground was provided by Medecins sans Frontieres (MSF) in March 2014. Not until August 8, 2014, did the World Health Organization (WHO) declare the Ebola epidemic a public health emergency of international concern. By then, MSF had described the outbreak as out of control [6]. It was hard for MSF to tone down its alarm and frustration. "Dead bodies in the street, families wiped out, dozens of health care workers infected, hospitals shut down and panic and mistrust in the eyes of the people in the streets," said Thomas Nierle, MSF President, and Bruno Jochum. MSF General Director [7]. According to them, the international response to Ebola was "slow, derisory, irresponsible"

Why is it that the international community is largely relying on the very fragile health systems in the affected countries to manage an international health crisis of this scope? And why are they entrusting global health security to private organisations that have, by nature, limited capacities to respond to major outbreaks? It is irresponsible to place exclusive management of such a devastating, deadly epidemic on the back of overwhelmed nations such as Sierra Leone and Liberia while praying that the private sector is filling the gaps left by the shortfalls of its heath system [7].

No international agency or Western governments stepped forward to take the driving seat in the global Ebola response until the WHO woke upin the last quarter of 2014. A year into the epidemic and thousands of deaths later, the WHO was forced to admit that it had been too slow to respond and announced a series of reforms in January 2015 including the creation of an emergency fund to respond to health crises, the establishment of a reserve of health workers to battle epidemics, and the ability to add or change staff with appropriate expertise at the country and regional level [8].

WHO's inherent weaknesses to respond to global health epidemics have been painfully clear. "The WHO we have is not the WHO we need," said Dr. Tom Frieden, director of the U.S. Centers for Disease Control and Prevention. He lamented that decisions at WHO were often made for political rather than scientific reasons [7]. It brought to mind the governance lacunae in the heydays of the AIDS crisis back in the 1980s. The Reagen administration was unresponsive to the "gay epidemic" until 1986 while the first years of multilateral cooperation within the UN through the Global Programme on AIDS was highly politicized and subsequently dissolved [3]. An intersectoral program, UNAIDS, was created in 1996, "premised on the technical competency, leadership and facilitating roles of the Secretariat and the Cosponsors at the various levelsand how they deliver results [9]". UNAIDS was charged with the mission of uniting UN efforts in conjunction with civil society, people living with AIDS, national governments, the private sector, and other global institutions; taking up a human rights agenda; mobilizing resources; empowering agents of change with information; and supporting inclusive country leadership [7]. Although underfunded and possessing little political clout vis-à-vis powerful states, UNAIDS has provided leadership in the global AIDS response over the past twenty years. Above all, the complexity of the AIDS epidemic helped foster a wide range of global health partnerships, such as the the Global AIDS Vaccine Initiative, the Alliance for Microbicide Development, and the African Comprehensive HIV/AIDS Partnerships. While there has been recognition that the Ebola crisis can only be reversed and future ones prevented if governments, international agencies, and the private sector work together, the devilish details have yet to be spelled out.

A particularly critical aspect of innovative governance is alternative financing. The AIDS epidemic taught us how important it was to reach beyond traditional bilateral and multilateral aid mechanisms. UNITAID was created in 2006 to strategically channel innovative funding to underserved health product markets, such as pediatric HIV treatments or cutting-edge diagnostic tools. Its business model is "commodity-driven" with the goal of developing sustainable and affordable health products. Over half of its funding comes from an airline levy, which ranges from $\$ 1$ for economy-class tickets to approximately $\$ 40$ for business- and first-class travel [10]. Since 2006, UNITAID has raised $\$ 2$ billion and funded projects in ninety-four countries. According to its executive director, the impact of UNITAID is not so much on financing per se, since the airline levy does not bring in a huge amount of money. Rather, "the impact is much more [from] using the small [amount of] money to reduce the price of second-line drugs, especially in pediatric ARV, . . and financing the WHO Prequalification Program, which [has] made forty-three drugs available since we started funding [11]". UNITAID's market initiative has resulted in price reductions of $10 \%$ to $40 \%$ for medicines and diagnostics [12]. Beyond the airline levy and initiatives such as Product Red-where 50\% of the profits go directly from the manufacturers to the Global Fund [13] a promising new avenue is a financial transaction tax (FTT), already adopted in various forms in over forty countries, which is expected to bring in an additional \$15 billion per year [14]. The current Ebola crisis shows us how unprepared the world is in meeting global health challenges. At the World Economic Forum in Davos in January 2015, World Bank President, Dr. Jim Yong Kim proposed afinancial "pandemic facility" that works like an insurance policy.

This could work like insurance policies that people understand, like fire insurance... The more that you are prepared for a fire, such as having several smoke detectors in your house, the lower the premium you pay... The more that countries, multi-lateral institutions, corporations and donors work together to prepare for future pandemics - by building stronger health systems, improved surveillance and chains of supply and transportation, and fast-acting medical response teams - the lower the premium as well [4].

Creating new governance structures and financing instruments has become an imperative in our ability to face unexpected global health crises. 


\section{Alternative Incentives for Biomedical Research and Development for Neglected Diseases}

Despite the rapid evolution of the disease in patients and high mortality rate that can reach $90 \%$, the sporadic nature of Ebola virus outbreaks and the relatively small number of people affected in Africa over the years have led to the general perception of the virus as a rare pathogen with little impact on also resulted in a lack of interest of developed countries and the pharmaceutical industry towards the disease until recently. Because the virus was perceived primarily as a potential bio weapon in the hands of terrorists, much of the research on Ebola was conducted behind closed doors in military facilities under secrecy, and/or as part of the Bio Shieldprogram in the US. Now, almost 40 years after the first virus detection, not much has been achieved to prevent or treat the infection in the general population.

Jocelyn Yelle, President of Antivirial Intelistrat Inc., Canada, 2014 [15].

Confronted with mounting deaths, it is hard not to ask the critical question: Why is there still no effective vaccine or treatment 40 years after the discovery of the Ebola virus? Two facts bear striking resemblance in the AIDS and Ebola epidemics: lackluster industry interest and underfunded national health research. In the case of AIDS, antiretroviral treatment was introduced in 1996 only after a full decade of activism for accelerated clinical trials and increased AIDS research funding. But treatment was priced out of reach for the majority of HIV-positive patients in developing countries in the ensuing decade and intellectual property (IP) issues remain a bottleneck in upscaling treatment. In the current Ebola outbreak, US National Institutes of Health (NIH) researchers published the first convincing evidence that an Ebola vaccine could protect monkeys back in 2000, but, according to one of the leading Ebola vaccine developers, Thomas Geisbert, "small global market has generated little commercial interest [16]." Anthony Fauci, Director of NIH"s National Institute of Allergy and Infectious Diseases and Francis Collins, NIH Director, agree that "big pharma's lack of interest in Ebola vaccine development is the main reason no product was ready for this epidemic [17]". Dr. Collins pinpointed the lack of research money as the cause of our failure to provide timely vaccines or therapeutics:

NIH has been working on Ebola vaccines since 2001. It's not like we suddenly woke up and thought, 'Oh my gosh, we should have something ready here'... Frankly, if we had not gone through our 10-year slide in research support, we probably would have had a vaccine in time for this that would've gone through clinical trials and would have been ready... [Treatments] were on a slower track than would've been ideal, or that would have happened if we had been on a stable research support trajectory [18].

The world cannot afford to wait for pharmceutical giants to weigh their economic interests against global public health. One of the most important lessons that emerged out of the AIDS epidemic has been the importance of alternative incentives for biomedical research and development for global neglected diseases. Recognizing the conundrum of competing economic and moral imperatives (the current incentives based on an IP regime fail to correct the complete neglect of developing countries' needs in life-saving products and millions die for lack of access to them), the Consultative Expert Working Group (CEWG) on Research and Developmentrecommends six concrete measures to rectify market failures in global neglected diseases in 2012: patent pools; an international convention on $\mathrm{R} \& \mathrm{D}$ for diseases prevalent in developing countries; open approaches to research and development in order to delink R\&D costs from product prices to promote access; direct grants to companies to promote capacity building and technology transfer to developing countries; pooled funding from various sources to subsidize R\&D costs; and milestone prizes and end prizes to provide incentives to researchers, especially those in developing countries [19]. All of these measures require sustainable sources of funding, which could include a new indirect tax (on arms trade, alcohol or tobacco sales, airline tickets, internet traffic, or bank transactions); voluntary consumer and business contributions; taxation on foreign pharmaceutical company profits; and new funds from nontraditional donors, like China and Venezuela. While there are currently some promising vaccines and therapeutic agents in the pipeline to fight Ebola infections, it will be too late for many of the currently affected populations by the time these become available. Besides vaccines and treatments, rapid, reliable, and accessible diagnostic tools are also important. Part of AIDS' success story in epidemic control is the availability of accurate, point-of-care, rapid tests that quickly identify infected patients within communities. In the current context of the Ebola crisis, PCR-based (polymerase chain reaction) diagnostic techniques are expensive, time-consuming, and available only in Ebola treatment centers. Arapid test that is made available at the community level, like in the case of HIV, has the potential to break the chain of transmission. We must act on the far-ranging recommendations of CEWG to provide alternative incentives for Pharma and national health centers to develop vaccines, treatment, and diagnostic tools for global neglected diseases.

\section{Health Systems Strengthening}

Ebola became epidemic in Guinea, Liberia, and Sierra Leone in large part because of their weak health systems. Particular weaknesses included insufficient numbers of qualified health workers, and inadequate surveillance and information systems. Other weaknesses include the absence of or weak rapid response systems, few laboratories - all located in cities - unreliable supply and procurement systems for PPEs and other supplies, lack of electricity and running water in some health facilities, few ambulances, and limited public health education, community outreach and engagement.

Dr. Marie-PauleKieny, WHO Assistant Director - General, Health Systems and Innovation [20]. 
A crisis often reveals and exacerbates existing health system weaknesses and constraints. One of the enduring lessons from the AIDS epidemic is that vertical funding for one disease could only go so far if a country's overall health system is crumbling. The structural adjustment programs of the World Bank had destroyed the health systems of many developing countries and prevented an effective AIDS response through its public spending cap including the salaries of healthcare workers. HIV response has been so well funded while health systems have been atrophied over the years. A particularly significant aspect of health system underfunding is the chronic shortage of healthcare workers that continues to undermine a robust AIDS response today.

A similar situation can be found in the current Ebola crisis. "The disaster is becoming even more dramatic as the health systems in the affected region have imploded. Patients are dying of Ebola, but also of malaria, diarrhoea or complicated deliveries due to the absence of effective medical care. In Liberia especially, hospitals are deserted. And fear is spreading," observes MSF [6]. A big part of the problem has been limited hospital space and facilities likeisolation centres as well as adequate trained doctors and nurses in the affected countries. According to Dr. Marie-PauleKieny, WHO Assistant Director-General in Health Systems and Innovation, "the answer to stopping Ebola outbreaks of this amplitude is strengthening health systems, yes. But more importantly than simply strengthening existing capacity for Ebola, countries need to create resilient integrated systems that can be responsive and proactive to any future threat [20]". A resilient health system requires integrated care rather than siloed programmes; strong lab and surveillance systems, and capacity to comply with the requirements of the International Health Regulations; an adequate pool of qualified health workers; and national ownership, local action, and full support of development partners [7].

\section{Community and Civil Society Engagement}

You have to know Ebola to fight Ebola. Mobilize your people.

Dr. Peter Clement, WHO Coordinator for Lofa County [21].

The impact of AIDS activism since the 1980s has resulted from three key roles taken up by community-based and civil society organizations: organizing and empowerment; voice and advocacy; and knowledge building. AIDS created a timely political opportunity for diverse communities, including gay men, sex workers, drug users, migrants, and youth, to organize themselves [3]. In the case of Ebola, grassroots engagement has been critical in detecting new cases, educating community members, and instigating behavioral change. In Sierra Leone, the International Rescue Committee organized 400 community volunteers in Kenema County to canvass 200,000 households in fourteen days and infection rates dropped [22]. In Kailahun district, one of the epicenters near the borders with Liberia and Guinea, a local community radio station, Radio MOA, together with other community-based organizations created an Ebola Response Task Force and organized a campaign to combat rumours. Every day, it transmits interviews with health experts, officials, and Ebola survivors on their "Watin Di Bi Nah Yu Community" "What is Happening in Your Community?") radio program, reaching tens of thousands of residents from across all three affected countries [23]. In Liberia, a community developed a communication mobilization plan that spread to all the households.

Ebola is a disease, not a curse, not a government plot. Those that are sick must go to the MSF clinic in Foya. No one can bury their loved ones anymore. Effective immediately they would call the people who do it safely. Although they are a very friendly people, there would be no more physical contact when greeting one another [21].

Engaging effectively with communities has been recognized as one of the keys to successfully driving cases to zero in many parts of Guinea, Liberia, and Sierra Leone. Like in the AIDS response, funding community-based and civil society organizations will prove to be cost-effective investments.

\section{Human Rights Protection}

West African governments should ensure rights protections as a crucial element in controlling the unprecedented Ebola epidemic ravaging the region. Governments in Ebola-affected countries should better protect health workers from infection, limit use of quarantines, address the gender dimensions of the outbreak, ensure security forces responding to the crisis respect basic rights, and facilitate independent monitoring of emergency measures and donations... Donor governments, through international assistance and cooperation, should help these governments fulfill the right to health and efforts to address the epidemic's broader impact.

Human Rights Watch, 2014.

Finally, an effective Ebola response must incorporate human rights protection. Here, the lessons from the AIDS crisis are illuminating. Nearly 35 years into the epidemic, while we have made phenomenal progress in terms of AIDS science, stigma and discrimination remain for people living with HIV and AIDS. In 2011, the UNAIDS Reference Group on HIV and Human Rights summarizes a human rights framework as five "nonnegotiables": (1) elimination of laws, policies, practices, stigma, and discrimination that block effective responses to AIDS; (2) universal access to HIV treatment; (3) funding commitments; (4) people living with HIV at the center of the response; and (5) a rights-based, shared AIDS governance [24]. We have seen in AIDS activism that some of the most significant victories-a free public ARV access program in Brazil; universal HIV treatment and public medical insurance in Thailand; the passage of the Medicines Amendment Act in South Africa to increase ARV access; and successful patent oppositions in India-happened when the right to health was enshrined in either the constitution, laws, policies, or amended patent acts [3]. 
In both the HIV and Ebola crises, we see "stigmatizing attitudes and behaviors, including patient blaming and neglect, refusal/ denial of care, and irrational and inappropriate fear of contagion directed toward impacted populations have not only devastated familial, social, and economic relationships and infrastructures but they have also interfered and created colossal barriers to access, prevention, and treatment [25]". In the case of HIV and AIDS, vulnerability is related to social marginality of people who use drugs, men who have sex with men, and sex workers. As homosexuality, drug use, and sex work are illegal inmost countries, a seropositive status doubles the stigma and discrimination. According to a meta literature review by Davtyan, Brown and Folaya (2014), HIV/AIDS-related stigma has led to "avoidance of healthcare, reduced adherence to antiretroviral medications, increased HIV symptomatology, and emergence of mental health pathologies including depression”. In the current Ebola outbreak, health services have been operating in a climate of fear and discrimination. Some patients and their families have been ostracized where Ebola is thought to be a result of witchcraft. Some patients with confirmed cases have evaded follow-up by medical teams. Fear has led to violence against medical and outreach personnel and compromised care delivery, transport of essential equipment and samples to laboratories, and proper burials, putting more individuals and communities at risk. Each month, security incidents are reported in Guinea, Liberia, and Sierra Leone.In addition, there is double stigma associated with Ebola and HIV infection. There have been community efforts including radio programs, songs, and grass roots education to fight against Ebola-related stigma.

In addition to the right to information and transparency, a rights response to Ebola includes proper oversight and monitoring; the right to life and health; an obligation to protect health workers; rights to liberty and freedom of movement as well as their livelihood; acknowledging the vulnerability of women; and ensuring the proper conduct of military personnel [26]. There has been reported fraud in the using of Ebola funds in Sierra Leone [27]. The governments of Guinea, Liberia, and Sierra Leone have put in place emergency measures that restrict basic rights and freedoms such as freedom of association, assembly, and movement. Health workers are not always promptly paid and the shortage of personal protective equipment for health care workers including rubber gloves, safety goggles, and protective suits has led to preventable health worker deaths. Quarantines have been imposed at different levels, on individual houses, neighborhoods, villages, or entire districts. Women are put at greater risk of due to their traditional role as caretakers and health workers or being infected by their partner through their semen for up to seven weeks after recovery. Police and soldiers enforcing quarantines in Liberia and Sierra Leone have been accused of soliciting bribes from people wanting to leave quarantined areas [23].

Ensuring the rights protection of affected communities means that governments need to be transparent and accountable about funding use and allocations. Emergency measures including quarantines must meet requirements of legality, evidence-based necessity, and proportionality [7]. Efforts need to be made to ensure women are able to access information about how to prevent and respond to the epidemic. State security forces must be trained to understand and adhere to the UN Code of Conduct for Law Enforcement Officials. The international community needs to contribute to these various efforts in ensuring rights protection in the Ebola response.

\section{Conclusion}

Thirty years of AIDS activism have taught us many invaluable lessons in responding to rapidly evolving global health epidemics.

In this article, I examined five of them: Innovative governance and financing; alternative incentives for biomedical research and development on neglected diseases; health systems strengthening; community and civil society engagement; and human rights protection. Despite very different contexts and demographics, there is a striking resemblance between the AIDS and Ebola epidemics in the major governance, funding, health systems, community mobilization, and human rights issues that impede an effective response to the current Ebola crisis. If we want to prevent more deadly future global epidemics, we must learn from the hard lessons from previous crises.

\section{References}

1. Heitz D (2014) How Ebola Is (and Is Not) Like HIV/AIDS. Healthline News.

2. Ebola Situation Report - 11 March 2015.

3. Chan J (2015) Politics in the Corridor of Dying: AIDS Activism and Global Health Governance 344.

4. BBC (2015) Ebola crisis: World 'dangerously unprepared' for future pandemics.

5. Baize S, Pannetier D, Oestereich L, Rieger T, Koivogui L, et al. (2014) Emergence of Zaire Ebola Virus Disease in Guinea. N Engl J Med 371: $1418-25$.

6. Medecins Sans Frontieres (2014) Ebola: the failures of the international outbreak response.

7. Women and HIV (2007) Association of Maternal and Child Health Programs.

8. WHO (2015) WHO Adopts Reforms to Repair Reputation After Bungling Ebola 1: 29.

9. Global Report (2010) UNAIDS Reporting on the Global AIDS Epidemic.

10. UNITAID (2013) Innovative Financing to Shape Markets for HIV/AIDS, Malaria and Tuberculosis.

11. Interview with the Executive Director, UNITAID, June 25, 2012.

12. Taufiqur Rahman (2013) Innovation to fund global health.

13. www.red.org/en/learn (2015). 
14. UNITAID (2015) Report on the Feasibility of A Financial Transaction Tax For Global Health and Development.

15. Yelle J (2014) The 2014 Ebola Virus Outbreak in West Africa: Current Perspectives for Prevention and Treatment. J Hum Virol Retrovirol 1: 2.

16. Geisbert TW, Jahrling PB (2003) Towards a vaccine against Ebola virus. Expert Rev Vaccines 2: 777-89.

17. Jon Cohen (2014) Fauci and Collins agree to agree on Ebola vaccine development and NIH funding.

18. Ebola Vaccine Would Likely Have Been Found By Now If Not For Budget Cuts: NIH Director (2014).

19. WHO (2012) Research and Development to Meet Health Needs in Developing Countries: Strengthening Global Financing and Coordination.

20. Kieny MP (2014) Ebola and health systems: Now is the time for change.

21. WHO (2014) Liberia: Working with communities is the key to stopping Ebola.

22. Ebola response in West Africa must include community engagement (2014).

23. Human Rights Watch (2014) West Africa: Respect Rights in Ebola Response.

24. UNAIDS (2011) UNAIDS Reference Group on HIV and Human Rights encourages UN Member States to focus on human rights ahead of High Level Meeting on AIDS.

25. Davtyan, Brown, Folaya (2014) Addressing Ebola-related Stigma: Lessons Learned from HIV/AIDS.

26. Human Rights Watch (2015) Cambodia: Labor Laws Fail to Protect Garment Workers.

27. Auditor General`s Findings On Ebola Fraud (2015). 